\title{
LEI No 12.736, DE 30 DE NOVEMBRO DE 2012: NOVA OPORTUNIDADE PARA A DETRAÇÃO PENAL OU REGRA PARA FIXAÇÃO DO REGIME INICIAL DE CUMPRIMENTO DE PENA?
}

\author{
RODRIGO DA SILVA PEREZ ARAÚJO
}




\title{
LEI No 12.736, DE 30 DE NOVEMBRO DE 2012: NOVA OPORTUNIDADE PARA A DETRAÇÃO PENAL OU REGRA PARA FIXAÇÃO DO REGIME INICIAL DE CUMPRIMENTO DE PENA?
}

Recebimento: $24 / 01 / 2013$

Aceite: 01/11/2013

Rodrigo Da Silva Perez Araújo ${ }^{1}$

\section{RESUMO}

O presente artigo tem por finalidade discorrer sobre algumas reflexões a respeito da inovação trazida ao art. 387 do CPP pela Lei ${ }^{\circ} 12.736$, de 30 de novembro de 2012. Apesar de recente, a inovação legislativa pouco inovou o ordenamento jurídico, haja vista o teor do Enunciado $\mathrm{n}^{\mathrm{o}} 716$ da Súmula do egrégio STF. O referido parágrafo incluído no CPP e a Súmula do egrégio STF, cumulados com os dispositivos da LEP e do CP, impõem ao juiz da fase de conhecimento computar o tempo de prisão provisória, de prisão administrativa ou de internação, no Brasil ou no estrangeiro, para o fim de determinação do regime prisional.

Palavras-Chave: Lei 12.736/2012. Convicção. Esquema de prisão. Sentença.

\begin{abstract}
This article aims to discuss a few ideas about the innovation brought to the CPP by the Law No 12.736 of November 30 of 2012. Despite beeing recent, it brought little innovation if you take into account the sawy of the Supreme Federal Court. The inovation included provisions

1 Pós-graduando em Direito Civil e Processo Civil pela UNIASSELVI. Participou dos cursos de especialização ministrados pela Escola do Ministério Público do Distrito Federal e Territórios e pela Escola da Magistratura do Tribunal de Justiça do Distrito Federal e Territórios. Juiz Substituto do Tribunal de Justiça do Tocantins. Email: rodrigop@tjto.jus.br.
\end{abstract}


of the LEP and The CP, bestow to the judge of the to compute the temporary detention time, of administrative detention or internment, in Brazil or abroad, for the purpose of determining the detention model.

Keywords: Law 12.736/2012. Conviction. Scheme of imprisonment. Sentence.

\section{INTRODUÇÃO}

Diante dos termos da Lei $\mathrm{n}^{\circ} 12.736$, de 30 de novembro de 2012, que incluiu o $\S 2^{\circ}$ ao artigo 387 do CPP, impõe-se computar "o tempo de prisão provisória, de prisão administrativa ou de internação, no Brasil ou no estrangeiro" "para fins de determinação do regime inicial de pena privativa de liberdade".

Ainda há dissenso na doutrina em formação a propósito da interpretação dessa recente inovação legislativa: uns propugnam sua aplicação literal; outros que deva prevalecer a voluntas legislatoris, de ordem a que o preceito determine não o regime inicial de cumprimento de pena, mas eventual progressão de regime em face da detração operada já na sentença; outros se manifestam no sentido de que a inovação seria inconstitucional, pois dispensaria tratamento jurídico diverso a pessoas em situação jurídica substancialmente semelhante, sem que o legislador tenha elegido critério razoável. Deve, portanto, ser proscrita do ordenamento jurídico etc.

A garantia constitucional do devido processo legal impõe limites à atividade legislativa, decorrentes, para o deslinde desta questão, do princípio da proporcionalidade e da isonomia 
substancial.

A norma legal deve ser razoável, adequada ao fim pretendido, restringir o direito fundamental com a intensidade apenas suficiente à concretização da finalidade ideada, e não dispensar tratamento jurídico diferente para pessoas em situações concretas substancialmente iguais. Não se pode olvidar que, uma vez publicada e vigente, integra o ordenamento jurídico, devendo integrá-lo validamente.

Ademais, é indubitável que, no momento em que se regulamenta nova lei, os debates legislativos sejam fundamentais para compreender a modificação legal, haja vista a natureza deôntica do Direito e a implementação da nova realidade que se quer plasmar.

A pretensão legislativa, como se vê na exposição de motivos do projeto de lei que culminou com a Lei $\mathrm{n}^{\mathrm{o}} 12.736$, de 2012, é a de evitar que o apenado "tenha que aguardar a decisão do juiz da execução penal, permanecendo nessa espera em regime mais gravoso ao que pela lei faz jus"2.

Procurou-se, portanto, ao que tudo indica, positivar o teor do Enunciado 716 da Súmula do Supremo Tribunal Federal, fazendo-o, entretanto, concessa venia, sem rigor técnico.

Em reforço:

O Supremo Tribunal Federal, quando da edição da Súmula 716, já fazia semelhante previsão, verbis: “Admi-

2 TEIXEIRA. Rejane Jungbluth. NEM TODA PRISÃO PROVISÓRIA PODE SER USADA PARA DETRAÇÃO. Disponível em: http://www.conjur.com.br/2012-dez-26/rejanejungbluth-nem-toda-prisao-provisoria-usada-detracao. Acesso em 9/1/2013. 
te-se a progressão de regime de cumprimento da pena ou a aplicação imediata de regime menos severo nela determinada, antes do trânsito em julgado da sentença condenatória". Ao juiz da execução era outorgada a competência de analisar o direito à progressão de regime ao preso provisório. Com a Lei 12.736, o juiz do conhecimento passa a ter essa mesma competência ${ }^{3}$. (g.n)

Os institutos jurídicos do regime inicial de cumprimento de pena e da progressão de regime não se confundem, mas substancial e teleologicamente se identificam: o primeiro é fixado em atenção à análise das circunstâncias judiciais e ao quantum de pena privativa de liberdade aplicada $\left(\mathrm{CP} \mathrm{n}^{\circ} 33, \S \S 2^{\circ}\right.$ e $3^{\circ}$, e LEP $n^{\circ} 110$ ); a progressão, diferentemente, tem em conta o tempo de cumprimento de pena mais "o mérito do condenado" "comprovado pelo diretor do estabelecimento" penal (CP n ${ }^{\circ} 33$, $\S 2^{\circ}$, e LEP $n^{\circ} 112$ ).

Tal diferenciação, como se percebe, não diz respeito à essência desses institutos, pois em ambas as hipóteses, a incidência da regra exige o preenchimento de um requisito objetivo e outro subjetivo: tempo e condições pessoais indicativas de ter o agente alcançado ou não um padrão comportamental socialmente desejado.

Percepção reveladora de que o programa normativo do art. $387, \S 2^{\circ}$, do CPP não afronta a vontade do legislador e da lei; 
antes, pode realizá-la.

Deve-se ter em conta que a aplicação da mera literalidade da regra em análise afrontaria, num só jato, a garantia constitucional da individualização da pena e a essência da execução penal ao induzir o entendimento de que a modificação do regime de cumprimento de pena dar-se-ia tão somente por cálculo aritmético, desprezando o esforço (ou não) do apenado em se reintegrar à comunidade mediante adoção de comportamento socialmente útil.

Com o que não se pode convir, pois o art. 112 da LEP não foi revogado expressamente ou por incompatibilidade lógica.

Com a devida vênia, não impressiona o argumento segundo o qual a natureza jurídica da prisão cautelar não se confunde com a da prisão em regime fechado, decorrente de sentença condenatória, disso decorrendo a correção da aplicação literal da novatio legis em comento.

Há décadas tem se aplicado a detração penal sem qualquer questionamento, consistente em abater do tempo de condenação o tempo de prisão cautelar. Em outras palavras, apesar de sua natureza instrumental, e por razões de equidade e para coarctar o bis in idem, a prisão cautelar identifica-se com a prisão-pena quando analisada do ponto de vista da restrição do direito fundamental à liberdade, devendo, por isso mesmo, ser computada, na pena definitivamente aplicada, depois do trânsito em julgado da condenação. Mas não se olvide que a detração, por si só, jamais determinou progressão automática de regime de cumprimento de pena. 
De outro modo, a lesão à garantia constitucional da isonomia substancial afigura-se evidente caso o dispositivo seja aplicado mediante interpretação apenas literal: é que poucos dias de prisão cautelar poderão implicar regime prisional menos severo, não se vislumbrando razoabilidade nessa circunstância quando cotejada com a possibilidade de o corréu, desafortunado com prisão cautelar por prazo inferior, estar obrigado a cumprir integralmente o requisito objetivo - além do subjetivo - para a progressão em regime mais gravoso.

Assim, desde um ponto de vista teleológico - redução do tempo consumido com a tramitação do processo e facilitação da colocação do apenado em liberdade - e sistemático - como exposto acima -, impõe-se convir que a norma não instituiu mais uma regra para a fixação do regime inicial de cumprimento de pena, mas, isto sim, criou mais um momento processual, desta vez no âmbito da ação penal condenatória, para verificação da possibilidade, ou não, de progressão de regime nos moldes do art. 112 da $\mathrm{LEP}^{4}$, providência já determinada ao Juízo das

4 (...) a norma não revogou o artigo 110 da Lei de Execução Penal, o qual reza: "O juiz, na sentença, estabelecerá o regime no qual o condenado iniciará o cumprimento da pena privativa de liberdade, observado o disposto no artigo 33 e seus parágrafos do Código Penal".

O parágrafo $2^{\circ}$ do artigo 387 do Código de Processo Penal deve ser interpretado como exigência de um novo capítulo da sentença condenatória, a posteriori da fase da dosimetria da pena. $\mathrm{O}$ sistema trifásico previsto no artigo 68 do Código Penal, assim como o exame do regime imposto para a pena - artigo 33 , parágrafo $3^{\circ}$ do Código Penal - e eventual unificação em caso de concurso de penas continuam inalterados. Somente após essa análise, é que se apreciará, se o caso, a incidência do parágrafo $2^{\circ}$ do artigo 387 do Código de Processo Penal.

Portanto, o juiz dedicará, na sentença, um capítulo próprio para a dosimetria da pena - como já fazia - no qual fixará o regime inicial de cumprimento com base na pena final aplicada na sentença, não considerando, nessa oportunidade, a "nova detração penal" oriunda da lei em comento.

Em seguida, em novo capítulo da sentença, o magistrado reconhecerá ou não o direito do réu à progressão de regime, caso este tenha tempo de prisão processual suficiente para tanto. 


\section{Execuções Penais, nos termos do Enunciado 716 da Súmula do Egrégio Supremo Tribunal Federal ${ }^{5}$.}

Desse modo, a pena definitiva e o verdadeiro regime inicial de cumprimento da pena, inclusive o que será indicado na carta de guia a ser enviada à Vara de Execução Penal, são aqueles determinados pelo artigo 110 da LEP, ou seja, os encontrados no capítulo da pena definitiva (e não naquela detraída da prisão preventiva já cumprida). É preciso rememorar que a pena definitiva não tem somente a função de fixação do regime inicial do cumprimento da pena, mas é também referência para o cômputo do prazo prescricional da pretensão punitiva ou executória, unificação de penas, indultos e comutações, benefícios para trabalho externo e saídas temporárias.

(Idem, ibidem).

5 De todo modo, a partir de um exemplo, podemos inferir as etapas que o juiz deverá ultrapassar para atender ao novo modelo oferecido. Ex.: sentença condenatória por crime de roubo, duplamente agravado, a pena definitiva em cinco anos e seis meses de reclusão. E em consonância com a Súmula n. 719 do Supremo Tribunal Federal: "A imposição do regime de cumprimento mais severo do que a pena aplicada permitir exige motivação idônea.", impõe o regime inicial fechado para cumprimento da pena. Contudo, tendo ficado preso por doze meses e sendo primário e sem antecedentes, o réu faz jus à progressão de regime prisional.

Caso se trate de réu com antecedentes negativos, melhor que o juiz se abstenha de aplicar o dispositivo em estudo, porquanto poderá estar invadindo seara de competência exclusiva do juiz das execuções penais. Aliás, o exemplo é bem claro, trata-se de réu sem qualquer mácula em seu passado. Atendida esta cautela, a fim de que inexista invasão de competência, indaga-se: como aplicar o regramento legal à situação estampada no exemplo? São dois momentos distintos: a) O juiz lançará em um capítulo do dispositivo, consoante art. 110, da Lei de Execuções Penais: "O Juiz, na sentença, estabelecerá o regime no qual o condenado iniciará o cumprimento da pena privativa de liberdade, observado o disposto no artigo 33 e seus parágrafos do Código Penal.", sua conclusão sobre a pena e o respectivo regime, ou seja, cinco anos e seis meses de reclusão, em regime fechado, além da multa; e, b) reservará outro para justificar a novidade.

Sugestão de redação: "Considerando que o réu fulano de tal está preso desde (...), ou seja, há (...) meses, tem direito à progressão de regime de cumprimento de pena, porquanto superado o percentual previsto no art. 112, da Lei de Execução Penal, nos termos do que dispõe o art. 387, $\S 2^{\circ}$, do Código de Processo Penal; em consonância, ainda, com o contido na Súmula n. 716, do Egrégio Supremo Tribunal Federal, segundo a qual 'Admite-se a progressão de regime de cumprimento da pena ou a aplicação imediata de regime menos severo nela determinada, antes do trânsito em julgado da sentença condenatória', faz jus ao regime semiaberto para início do cumprimento de sua pena. Oficie-se à prisão em que se encontra".

Lembre-se que, em caso de crimes hediondos ou assemelhados, a menção à Lei 8.072/90, art. $2^{\circ}$, $\S 2^{\circ}$, é imperativa: "A progressão de regime, no caso dos condenados aos crimes previstos neste artigo, dar-se-á após o cumprimento de $2 / 5$ (dois quintos) da pena, se o apenado for primário, e de $3 / 5$ (três quintos), se reincidente".

Dentro da competência que ora lhe é confiada, o juiz da condenação, no caso de progressão de regime semiaberto para aberto, designará data para a audiência correspondente (de regime aberto) e concederá ao réu o direito de aguardar a solução do processo em liberdade, eis que se mostra desnecessária a manutenção da custódia cautelar.

Em qualquer situação, mostra-se conveniente que o magistrado sentenciante determine, antes de proferir a decisão, a juntada do atestado de bom comportamento carcerário, em atendimento ao 


\section{A propósito:}

Por fim, importante registar que esta inovação legislativa, promovendo inesperada e repentina interação entre as jurisdições penais de conhecimento e executiva, parece partir do pressuposto de que a progressão de regime é um mero procedimento de cálculo aritmético de cumprimento de pena, ignorando que está condicionada por lei à aferição do mérito do apenado para passar de um regime mais gravoso a outro.

Ainda que a redação artigo 112 da LEP, desde a edição da lei 10.783/03, tenha passado a exigir para a verificação do mérito na progressão simples atestado de bom comportamento carcerário, a jurisprudência já vem entendendo que o juiz preservou a faculdade de exigir a demonstração de progresso do apenado no processo de ressocialização por meio de laudos técnicos (parecer

contido no caput, do art. 112, da LEP.

Mas e, se ainda assim, o juiz se sentir inseguro quanto a real situação pessoal do acusado? Deve converter o julgamento em diligência, com a urgência que o caso requer para juntada de nova Folha de Antecedentes. Esta e o atestado são os requisitos objetivos para deslinde do quadro.

Finalmente, dois aspectos devem ser reforçados: a) a competência para conceder a detração penal, outrora conferida exclusivamente ao juiz das execuções (LEP, art. 66, III, al. c), agora é identicamente outorgada ao juiz da condenação, dentro dos limites ora pontuados, tratando-se de um juízo provisório de progressão prisional; b) se o período de prisão provisória ou de internação não conduzir ao direito de progressão de regime, ou os antecedentes do réu sugerirem avaliação mais detida por parte do juiz das execuções, simplesmente deverá ser ignorado o preceito legal; salvo se a defensoria pleiteou a benesse nos debates orais ou memoriais, quando será obrigado a fundamentar o indeferimento, pena de ofensa ao direito de ampla defesa.

4. Guia de Recolhimento.

Esta tem como fonte primeira o capítulo relativo à pena imposta e seu regime de cumprimento que, no exemplo citado, foi o fechado (LEP, art. 110). No entanto, a progressão de regime concedida pelo juiz de conhecimento deverá constar do documento, ainda que inexistam campos específicos para tal fim. Esta medida visa evitar prejuízos ao acusado e transmitir ao juiz das execuções o alcance da sentença prolatada. Não é por outra razão que o art. $106, \S 2^{\circ}$, da LEP, ao tratar da guia definitiva prescreve que: "A guia de recolhimento será retificada sempre que sobrevier modificação quanto ao início da execução ou ao mesmo tempo de duração da pena" (FREITAS, Jayme Walmer de. A detração penal à luz da Lei $n^{\circ}$ 12.736/2012. Jus Navigandi, Teresina, ano 18, n. 3491, 21 jan. 2013. Disponível em: <http://jus.com.br/revista/texto/23509>. Acesso em: 23 jan. 2013. 
criminológico), devendo tal faculdade ser observada pelos juízes na aplicação da lei nova, negando-se a progressão quando entenderem que o resguardo da ordem pública exige uma aferição mais acurada do mérito do apenado, incompatível com a fase da prolação da sentença condenatória.

Com efeito, a execução penal perderia completamente seu sentido de ser um processo de individualização da pena se a progressão de regime não pudesse estar sujeita a um juízo sobre a capacidade provável de adaptação do condenado a uma nova situação menos restritiva de liberdade, tendo em vista especialmente a necessidade de resguardar o convívio social de pessoas que ainda representem um perigo para a ordem pública ${ }^{6}$.

Assim, após a fixação do regime inicial de cumprimento de pena nos moldes do art. 110 da LEP, deve o magistrado, em outro capítulo da sentença, por versar questão própria e diversa, analisar se o acusado preenche os requisitos objetivo e subjetivo descritos no art. 112 da LEP, cuidando para que eventual detração seja anotada na guia de execução, evitando-se o abatimento dobrado do tempo de prisão cautelar, e para a designação de audiência admonitória, conforme o caso.

\section{REFERÊNCIAS}

\section{ARAÚJO, Antônio Cláudio Linhares. A nova lei de detração penal: dúvidas interpretativas $\mathrm{e}$ o “jeitinho}

6 ARAÚJO, Antônio Cláudio Linhares. A nova lei de detração penal: dúvidas interpretativas e o "jeitinho brasileiro". Disponível em <http://www.migalhas.com.br/ dePeso/16,MI168482,41046-A+nova+lei+de+detracao+penal+duvidas+interpretativas + e + o + jeitinho>. Acesso em: 15 jan. 2013. 
brasileiro". Disponível em <http://www.migalhas.com.br/ dePeso/16,MI168482,41046-A+nova+lei+de+detracao+pena $1+$ duvidas + interpretativas $+\mathrm{e}+\mathrm{o}+$ jeitinho $>$. Acesso em $15 \mathrm{jan}$. 2013.

BRASIL. Decreto-lei $\mathbf{n}^{\mathbf{2}} \mathbf{2 . 8 4 8}$, de 7 de dezembro de 1940 . Código Penal. Publicado no DOU em 31.12.1940.

BRASIL. Lei $\mathbf{n}^{\mathbf{0}}$ 12.736, de 30 de novembro de 2012. Dá nova redação ao art. 387 do Decreto-Lei no 3.689, de 3 de outubro de 1941 - Código de Processo Penal, para a detração ser considerada pelo juiz que proferir sentença condenatória. Publicado no DOU em 03.12.2012.

BRASIL. Lei n $^{\mathbf{7 2 1 0}}$, de 11 de Julho de 1984. Institui a Lei de Execução Penal. Publicado no DOU em 13.07.1984.

FREITAS, Jayme Walmer de. A detração penal à luz da Lei no 12.736/2012. Jus Navigandi, Teresina, ano 18, n. 3491, 21 jan. 2013 . Disponível em: <http://jus.com.br/revista/texto/23509>. Acesso em: 23 jan. 2013.

TEIXEIRA. Rejane Jungbluth. Nem toda prisão provisória pode ser usada para detração. Disponível em: <http://www. conjur.com.br/2012-dez-26/rejane-jungbluth-nem-toda-prisaoprovisoria-usada-detracao>. Acesso em: 09 jan. 2013. 
TRIBUNAL DE JUSTIÇA DO ESTADO DO TOCANTINS 